\title{
In vitro Activation of Human and Rat Lymphocyte and Macrophage Functions by Norepinephrine
}

\author{
${ }^{1}$ Ricardo Gomez-Flores, ${ }^{1}$ Diana Caballero-Hernandez, ${ }^{2}$ Richard J. Weber, ${ }^{1}$ Reyes Tamez-Guerra, ${ }^{1}$ Patricia \\ Tamez-Guerra and ${ }^{1}$ Cristina Rodriguez-Padilla \\ ${ }^{1}$ Departamento de Microbiología e Inmunología, Laboratorio de Inmunología y Virología, Facultad de \\ Ciencias Biológicas, Universidad Autónoma de Nuevo León, San Nicolás de los Garza, NL, México \\ ${ }^{2}$ Department of Biomedical and Therapeutic Sciences, UIC College of Medicine, Peoria, IL.
}

\begin{abstract}
Norepinephrine (NE) has been associated not only with increasing blood pressure, atherosclerosis, heart disease, and other life threatening conditions, but also with altering immune responses by influencing leukocyte functions. In the present study, we evaluated the in vitro effects of $\mathrm{NE}$ on rat thymic lymphocyte and human peripheral blood mononuclear cells (HPBMC) functions. We observed that NE marginally, but significantly $(\mathrm{P}<0.01)$ enhanced $(1.3$-fold increase) proliferation of rat thymic lymphocytes at $10^{-5} \mathrm{M}$, without altering HPBMC proliferation, as compared with untreated control. In addition, NE $\left(10^{-5} \mathrm{M}\right)$ significantly $(\mathrm{P}<0.01)$ enhanced nitric oxide production $(2.9 \pm 0.095$ $\mathrm{nmol} /$ well) (which reduced $20 \%$ cell viability), and stimulated $(\mathrm{P}<0.01)$ TNF- $\alpha$ production $(4+0.16$ $\mathrm{pg} / \mathrm{ml})$ by rat macrophages. NE $\left(10^{-5} \mathrm{M}\right)$ was also observed to induce 2 -fold increase in mRNA signal of TNF- $\alpha$, and stimulated that of IL-1 and IL-6 by HPBMC, as compared with untreated control. Taken together, these results indicated that $\mathrm{NE}$ was capable to activate in vitro rat and human lymphocyte and macrophage pro-inflammatory response.
\end{abstract}

Key words: Norepinephrine, immunomodulation, proliferation, nitric oxide, TNF- $\alpha$, inflammatory cytokines, lymphocytes, macrophages, rat, human.

\section{INTRODUCTION}

It is well recognized that during an immune response, homeostasis is maintained by the interaction between the brain and the immune system ${ }^{[1]}$, and the consequent sharing of cytokines, peptide hormones, neurotransmitters, and receptors for these molecules ${ }^{[2]}$. It is then important to understand the bi-directional communication and regulation of the immune and nervous systems. Norepinephrine (NE) is the principal neurotransmitter released from sympathetic nervous system $^{[3]}$, associated with regulation of autonomic activity within the body by increasing metabolism, increasing heart rate and respiration, dilating the pupils, increasing perspiration, and improving the flow of oxygen to the major muscle groups ${ }^{[4]}$. However, chronic NE release commonly relates to life threatening conditions such as high blood pressure, atherosclerosis, heart disease, and other ${ }^{[5]}$. Release of NE from the sympathetic nerve terminals within lymphoid organs, and the presence of adrenoreceptors on lymphocytes and macrophages, suggest an additional pathway of immunoregulation by the central nervous system ${ }^{[6,7]}$. Adrenergic agonists have been shown to regulate function of immune cells, leading to alteration of cytokine production, lymphocyte proliferation, lymphocyte traffic, and antibody secretion ${ }^{[8-10]}$.

The present study was designed to evaluate the effects of NE on rat and human lymphocyte proliferation, and macrophage inflammatory activities following in vitro stimulation. We found that $\mathrm{NE}$ stimulated pro-inflammatory parameters of leukocyte functions.

\section{MATERIALS AND METHODS}

Reagents, culture media, and cell lines: Penicillinstreptomycin solution, L-glutamine, ficoll-hypaque solution, trypsin-EDTA solution, and RPMI 1640 and AIM-V media were obtained from Life Technologies (Grand Island, NY). Norepinephrine, fetal bovine serum (FBS), concanavalin A (Con A), phytohemaglutinin (PHA), lipopolysaccharide (LPS) from Escherichia coli serotype 026:B6, sodium dodecyl sulfate (SDS), N,N-dimethylformamide (DMF), dimethyl sulfoxide (DMSO), PBS, and 3-[4,5dimethylthiazol-2-yl]-2,5-diphenyltetrazolium bromide (MTT) were purchased from Sigma Chemical Co. (St. Louis, MO). The murine fibrosarcoma L929 (clone CCL 1) was purchased from the American Type

Corresponding Author: $\quad$ Ricardo Gomez-Flores, Ph.D., Río Guadalquivir 402 B-Ote., Colonia del Valle, San Pedro Garza García, Nuevo León, México, C.P. 66220. Tel: (83) 29-41-10 x 6453; fax: (83) $52-42-12$ 
Culture Collection (Rockville, MD) and was maintained in RPMI 1640 medium supplemented with $10 \%$ FBS, $1 \%$ L-glutamine, and $0.5 \%$ penicillinstreptomycin solution (referred as complete RPMI 1640 medium). Extraction buffer was prepared by dissolving $20 \%(\mathrm{wt} / \mathrm{vol}) \mathrm{SDS}$ at $37 \mathrm{oC}$ in a solution of $50 \%$ each $\mathrm{DMF}$ and demineralized water, and the $\mathrm{pH}$ was adjusted to 4.7 .

Animals: Sprague-Dawley male rats (200-220g) were purchased from Harlan Sprague-Dawley Inc. (Indianapolis, IN). They were kept in a pathogen- and stress-free environment at 240C, under a light-dark cycle (light phase, 06:00-18:00 h), and given water and food ad libitum. Animals were euthanized by asphyxiation in $100 \%$ CO2 chamber.

Cell preparation and culture: Thymus was immediately removed after rat death. Single-cell suspensions were prepared by disrupting the thymus in RPMI 1640 medium. Cell suspensions were then washed three times in this medium, and suspended and adjusted to $1 \times 10^{7}$ cells $/ \mathrm{ml}$ with AIM-V medium. The culture medium was changed at this step to the serumfree medium AIM-V which has been observed to support cell culture ${ }^{[11]}$. Peritoneal macrophages were prepared by lavaging the peritoneal cavity with cold RPMI 1640 medium, and washing the resulting cell suspension twice in this medium. One hundredmicroliter cell suspensions at $1.7 \times 10^{6}$ cells $/ \mathrm{ml}$ in AIM-V medium were then plated in flat-bottomed 96well plates (Becton Dickinson, Lincoln Park, NJ) for 2 $\mathrm{h}$ at $37^{\circ} \mathrm{C}$. Non-adherent cells were removed, and adherent cells (about $70 \%$ of the input cells or about $1 \mathrm{x}$ $10^{6}$ cells $/ \mathrm{ml}$ ) were then utilized for determining nitric oxide and tumor necrosis factor-alpha (TNF- $\alpha$ ) production. The final adherent cell monolayer consisted of $95-99 \%$ macrophages as judged by Giemsa's stain procedures.

T cell proliferation assay: $T$ cell proliferation was determined by a colorimetric technique using $\mathrm{MTT}^{[12]}$. Thymic cell suspensions $(100 \mu \mathrm{l})$ were added to flatbottomed 96-well plates (Becton Dickinson) containing triplicate cultures $(100 \mu \mathrm{l})$ of AIM-V medium (unstimulated control) or $\mathrm{NE}$ at various concentrations. After incubation for $44 \mathrm{~h}$ at $37^{\circ} \mathrm{C}$ with $5 \% \mathrm{CO}_{2}$, MTT $(0.5 \mathrm{mg} / \mathrm{ml}$, final concentration) was added, and cultures were additionally incubated for $4 \mathrm{~h}$. Cell cultures were then incubated for $16 \mathrm{~h}$ with extraction buffer $(100 \mu \mathrm{l})$ and optical densities, resulting from dissolved formazan crystals, were then read in a microplate reader (Bio-Tek Instruments, Inc., Winooski, VT) at $540 \mathrm{~nm}$.
Nitrite determination: Accumulation of nitrite in the supernatants of macrophage cultures was used as an indicator of nitric oxide production by resident or activated cells. Peritoneal macrophages were incubated for $72 \mathrm{~h}$ in $200 \mu \mathrm{l}$ AIM-V medium, in the presence or absence of various concentrations of NE or LPS (20 $\mathrm{ng} / \mathrm{ml}$ ) in triplicates, in a total volume of $200 \mu \mathrm{l}$ AIM-V medium. After incubation, supernatants were obtained and nitrite levels were determined with the Griess reagent ${ }^{[13]}$, using $\mathrm{NaNO}_{2}$ as standard. Optical densities at $540 \mathrm{~nm}$ were then determined in a microplate reader (Bio-Tek Instruments, Inc.). Macrophage viability was determined by the MTT reduction assay as previously described $^{[12]}$.

The percentage of viability was calculated as follows:

$$
\% \text { viability }=\frac{\mathrm{A}_{540} \text { in NE-treated cells }}{---\mathrm{A}_{540} \text { in untreated cells }}
$$

TNF- $\alpha$ assay: TNF- $\alpha$ levels in rat macrophage culture supernatants were determined by the L929 bioassay. In brief, peritoneal macrophage monolayers were incubated in the presence or absence of NE $\left(10^{-5} \mathrm{M}\right)$ or $20 \mathrm{ng} / \mathrm{ml} \mathrm{LPS}$, in a total volume of $200 \mu \mathrm{l}$ of AIM-V medium for $4 \mathrm{~h}$, after which supernatants were collected and kept at $-80^{\circ} \mathrm{C}$ until use. TNF- $\alpha$ levels in the supernatants were then quantified by the L929 bioassay as described elsewhere ${ }^{[13]}$. This bioassay was performed in complete RPMI 1640 medium using 1/3 serial dilutions of the supernatants. Recombinant murine TNF- $\alpha$ (a gift from NCI Biological Resources Branch, Rockville, MD, lot 88/532) was used as standard. After $24 \mathrm{~h}$ of incubation, cell viability of L929 cells was determined by a colorimetric technique using MTT to a final concentration of $0.5 \mathrm{mg} / \mathrm{ml}$, and incubating the cells for $1.5 \mathrm{~h}$ at $37^{\circ} \mathrm{C}^{[14]}$. After the incubation period, supernatants were discarded, and formazan crystals were dissolved in DMSO. Optical densities were then determined in a microplate reader (Molecular Devices Corporation) at $540 \mathrm{~nm}$. TNF- $\alpha$ levels $(\mathrm{pg} / \mathrm{ml})$ were determined using a recombinant murine TNF- $\alpha$ standard curve.

Effect of NE on human leukocytes: Mononuclear leukocytes were obtained from peripheral blood (HPBMC) of a healthy 18-year old female volunteer, and centrifuged in a $1.077 \mathrm{~g} / \mathrm{dl}$ ficoll-hypaque solution for $30 \mathrm{~min}$ at $10^{\circ} \mathrm{C}$ and $1600 \mathrm{rpm}$. The recovered mononuclear cells were washed twice in RPMI 1640 medium, and adjusted to $5 \times 10^{6}$ cells $/ \mathrm{ml}$ in AIM-V medium. One hundred microliters of the leukocyte suspension was then incubated in the presence or absence of various concentrations of NE. Cell cultures were then incubated for $44 \mathrm{~h}$ at $37^{\circ} \mathrm{C}$ in $5 \% \mathrm{CO}_{2}$. After incubation, MTT $(0.5 \mathrm{mg} / \mathrm{ml}$, final concentration) was 
added, and cultures were additionally incubated for $4 \mathrm{~h}$. Cell cultures were then incubated for $16 \mathrm{~h}$ with extraction buffer $(100 \mu \mathrm{l})$ and optical densities, resulting from dissolved formazan crystals, were then read in a microplate reader (Bio-Tek Instruments, Inc.) at $540 \mathrm{~nm}$.

Inflammatory cytokine gene expression in HPBMC: Whole HPBMC were incubated for $16 \mathrm{~h}$ in the presence or absence of PHA $(20 \mu \mathrm{g} / \mathrm{ml})$. PHA-treated samples were then incubated for 5 additional hours at $37^{\circ} \mathrm{C}$, $95 \% \mathrm{CO} 2-5 \%$ air, in the presence or absence of NE $\left(10^{-}\right.$ $\left.{ }^{5} \mathrm{M}\right)$. After this, mononuclear cells were obtained by centrifugation on a ficoll-hypaque gradient. The recovered mononuclear cells were washed twice in RPMI 1640 medium, and adjusted to $5 \times 10^{6}$ cells $/ \mathrm{ml}$ in AIM-V medium. Next, trizol was added to the cells to extract total RNA. Gene expression for inflammatory cytokines was then detected by RT-PCR as reported elsewhere $^{[15]}$.

Statistical analysis: The results were expressed as mean \pm SEM of the response of 3 separate rat thymuses or HPBMC samples to each treatment (3 replicate determinations per treatment) from three independent experiments. Level of significance was assessed by Student's $t$ test and analysis of variance (ANOVA).

\section{RESULTS}

Effect of NE on lymphoproliferation: As observed in Figure 1, NE marginally (1.3-fold increase), but significantly $(\mathbf{P}<0.01)$ enhanced proliferation of rat thymic lymphocytes at the highest concentration tested $\left(10^{-5} \mathrm{M}\right)$. There was no effect of NE on HPBMC. For comparison, rat thymic lymphocyte proliferation indexes to concanavalin A at concentrations of $0.6,1.2$, and $2.4 \mu \mathrm{g} / \mathrm{ml}$ were $2.6,3.4$ and 1.05 respectively (data not shown).

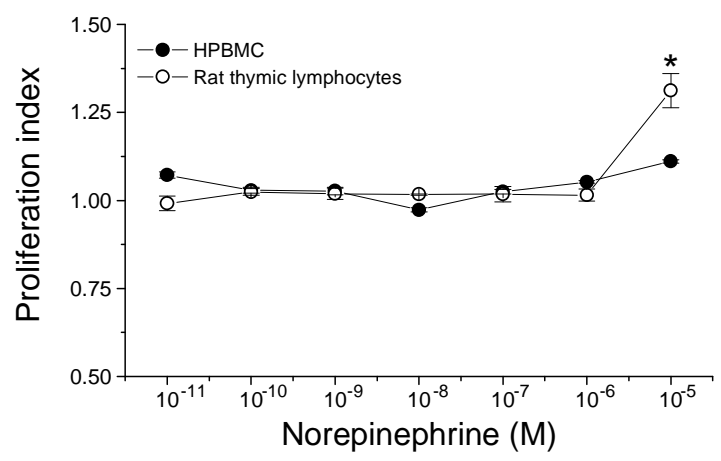

Fig. 1: Rat thymic leukocyte and HPBMC proliferation induced by NE. Thymic cells and HPBMC were cultured in the presence or absence of AIM-V medium (unstimulated control) or NE at various concentrations for $44 \mathrm{~h}$ at $37^{\circ} \mathrm{C}$ in $5 \% \mathrm{CO}_{2}$, after which leukocyte proliferation was determined by a colorimetric technique using MTT, as detailed in the text. Data represent mean \pm SEM of triplicates from a representative experiment. $* \mathbf{P}<0.01$ as compared with untreated control. Proliferation index indicates the cell response of NE-treated cells divided by that of untreated cells. Optical densities at $540 \mathrm{~nm}$ for untreated rat thymic lymphocytes and HPBMC were $0.484 \pm 0.02$ and $0.366 \pm 0.008$ respectively.

Effect of NE on nitric oxide and TNF- $\alpha$ production by macrophages: Nitrite levels in supernatants of rat macrophage cultures treated with $\mathrm{NE}\left(10^{-5} \mathrm{M}\right)$ were significantly $(\mathbf{P}<0.01)$ higher $(2.9 \pm 0.095 \mathrm{nmol} / \mathrm{well})$ than those of untreated control $(2.1 \overline{7} \pm 017 \mathrm{nmol} /$ well $)$ (Fig. 2a). For comparison, nitrite levels induced by LPS at concentrations of $20 \mathrm{ng} / \mathrm{ml}$ were $8.2 \pm 0.2 \mathrm{nmol} /$ well (data not shown). $\mathrm{NE}$ at $10^{-5} \mathrm{M}$ was associated with $20 \%$ reduction of viability (Fig. 2a). At this concentration, NE significantly $(\mathbf{P}<0.01)$ stimulated TNF- $\alpha$ production by macrophages $(4 \pm 0.16 \mathrm{pg} / \mathrm{ml})$ as compared with negligible TNF- $\alpha$ levels observed in untreated control (Fig. 2b). For comparison, TNF- $\alpha$ levels induced by LPS at concentrations of $20 \mathrm{ng} / \mathrm{ml}$ were $8 \pm 0.8 \mathrm{pg} / \mathrm{ml}$ (Fig. 2).
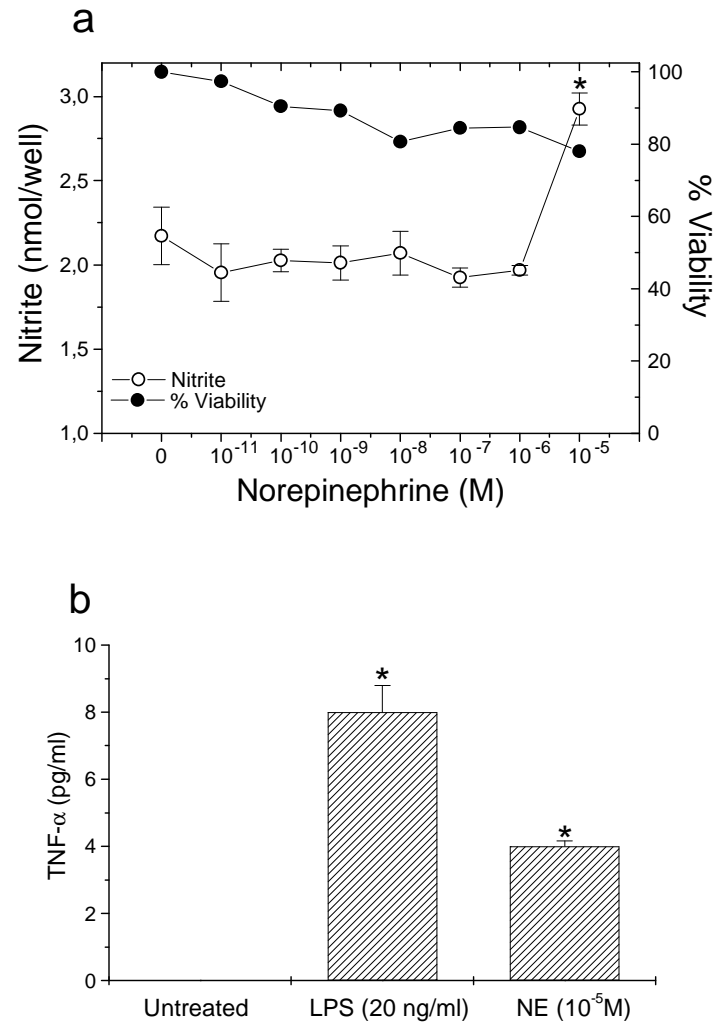
Fig. 2. Nitric oxide and TNF- $\alpha$ production by rat macrophages. Peritoneal cells were incubated overnight, after which adherent cells $\left(1 \times 10^{6}\right.$ cells $/ \mathrm{ml}$ ) were washed once and incubated for $4 \mathrm{~h}$ (TNF- $\alpha$ determination) and $72 \mathrm{~h}$ (nitrite determination) at $37^{\circ} \mathrm{C}$, in the presence or absence of NE or LPS (20 ng/ml). Supernatants were then collected and tested for nitrite $(a)$ and TNF- $\alpha(b)$ levels. $* \mathrm{P}<0.01$ compared with untreated control. LPS alone $(20 \mathrm{ng} / \mathrm{ml})$ induced the production of $8.2 \pm 0.2$ $\mathrm{nmol} /$ well by peritoneal macrophages $(100 \%$ viability).

Effect of NE on inflammatory cytokine gene expression by HPBMC: In addition to measuring the effects of NE on some parameters of immune function in rat and human lymphocytes and macrophages, and because human macrophages possess limited capacity to produce nitric oxide, we evaluated the effects of NE on inflammatory cytokine gene expression and viability of HPBMC. As observed in Figure 3, NE increased the signal of TNF- $\alpha$, IL-1 and IL- 6 mRNA by human leukocytes, as compared with untreated and PHAtreated controls. $\mathrm{NE}$ at concentrations of $10^{-5} \mathrm{M}$ induced 2-fold increase in TNF- $\alpha$ mRNA signal (EpiChemi Darkroom, Labworks software v. 3, Ultra-Violet Products, Upland, CA), and stimulated IL-1 $\beta$ and IL-6 mRNA signals, as compared with untreated control; whereas PHA treatment caused 1.33-fold increase in TNF- $\alpha$ mRNA signal without stimulating IL- $1 \beta$ and IL6 mRNA signals, as compared with untreated control (Fig. 3) (house-keeping gene G3PDH signal was the same for all experimental conditions, including the untreated control). NE was also observed not to alter human leukocytes viability (data not shown).

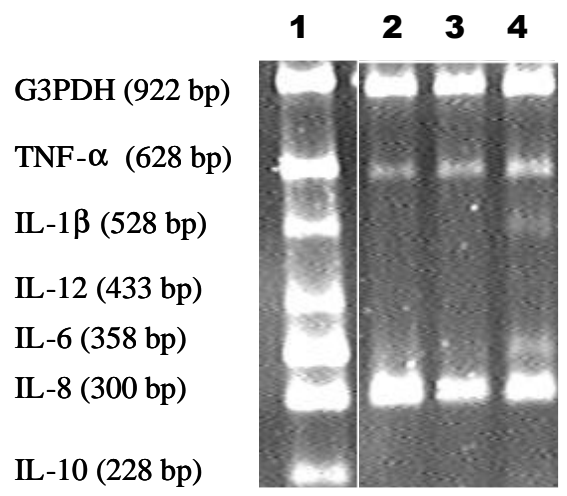

Fig. 3. Inflammatory cytokine gene expression in HPBMC induced by NE. HPBMC were adjusted to $5 \times 10^{6}$ cells $/ \mathrm{ml}$ in AIM V medium as explained in the text. One hundred microliters of the leukocyte suspension was then incubated in the presence or absence of $\mathrm{NE}\left(10^{-5} \mathrm{M}\right)$ or PHA $(20 \mu \mathrm{g} / \mathrm{ml})$. Cell cultures were then incubated for $5 \mathrm{~h}$ and processed as detailed in the text. Lane 1, mRNA cytokine markers; lane 2, untreated control; lane 3, PHA treatment; and lane 4, NE treatment.

\section{DISCUSSION}

In the present study, we reported in vitro activation of rat thymic lymphocyte proliferation, and macrophage production of nitric oxide and TNF- $\alpha$, and increased mRNA signal of the HPBMC pro-inflammatory cytokines TNF- $\alpha$, IL-1 and IL- 6 by NE in-vitro. NE has been shown to activate $\mathrm{TH} 2$ cell-dependent antibody response in vivo ${ }^{[9]}$, and in combination with IL-12, was shown to increase the pool of TH1 cells ${ }^{[16]}$. In contrast, $\mathrm{NE}$ was reported to suppress proliferation of rat peripheral blood T-lymphocytes ${ }^{[17]}$ (which may be related to catecholamine-induced apoptosis ${ }^{[18]}$ ), decrease IL-2 production by murine splenic naïve CD4+ T cells ${ }^{[19]}$, and inhibit IFN- $\gamma$ synthesis by PHAstimulated splenic cells ${ }^{[20]}$. Additionally, A significant suppression of IL-1, IL-2, IL-4, and IFN- $\gamma$ interferon production by splenic leukocytes, and proliferative response of splenic $\mathrm{T}$ lymphocytes following immunization with sheep red blood cells, was observed in the reeler $(\mathrm{rl} / \mathrm{rl})$ mice (a neurologic mutant strain with an abnormally high concentration of cerebellar $\mathrm{NE})^{[21]}$. NE was also observed to inhibit human naturalkiller $(\mathrm{NK})$ cell cytotoxicity ${ }^{[22,23]}$; however, NE was shown to increase the unstimulated, the interleukin-2 and interferon-alpha stimulated NK cell activity ${ }^{[24]}$.

In the macrophage, NE has been involved in suppression of IL-12 production and enhancement of IL-10 release by lipopolysaccharide- or keyhole limpet hemocyanin-stimulated bone marrow-derived dendritic cells $^{[25]}$. NE was also reported to decrease TNF- $\alpha$ mRNA by activated macrophages ${ }^{[26]}$, decrease LPSstimulated rat splenic macrophages production of TNF$\alpha$ at $10 \mu \mathrm{M}^{[27]}$, and inhibited IL- 1 production by IFN- $\gamma$ and LPS-activated murine peritoneal macrophages ${ }^{[28]}$. In addition, $\mathrm{NE}$ at concentrations ranging from $10^{-8}$ to $10^{-5} \mathrm{M}$, was shown to enhance HIV-1 replication by suppressing proinflammatory cytokine production ${ }^{2}$. In contrast, NE increased TNF- $\alpha^{[10]}$, LPS-induced TNF$\alpha^{[29]}$, and nitric oxide production ${ }^{[30,31]}$, and phagocytosis $^{[32]}$ by macrophages, but suppressed inducible nitric oxide synthase activity in rat astroglial cultures $^{[33]}$. These conflicting reported findings, along with our results, on the in vitro action of NE on immune function may be related to several factors including: a) activation of different adrenoceptors ${ }^{[34-39]}$, b) cell source 
and NE concentration utilized, c) via of opioid administration, and d) duration of treatment.

Norepinephrine is known to act on adrenoceptors present in lymphocytes, macrophages, neutrophils and thymic epithelial cells ${ }^{[34,35]}$. Despite its high-affinity binding to $\alpha 1, \beta 1$, and $\beta 3$ adrenoceptors ${ }^{[36-39]}$, NE inhibits the production of the pro-inflammatory cytokines IL-1, TNF- $\alpha$, and IFN- $\gamma$ and stimulate the production of the anti-inflammatory cytokines IL-10 and transforming growth factor-beta, through stimulation of the $\beta 2$-adrenoreceptor-cAMP-protein kinase A pathway ${ }^{[40]}$; furthermore, $\mathrm{NE}$ at $10^{-5} \mathrm{M}, 10^{-6}$ $\mathrm{M}$, and $10^{-7} \mathrm{M}$ was reported to suppress IFN- $\gamma$ production, but at $10^{-5} \mathrm{M}$, enhanced IL-10 production through $\alpha 2$-adrenoceptor activation ${ }^{[41]}$. However, under certain conditions, NE may boost regional immune responses, through induction of IL- 1 , TNF- $\alpha$, and IL-8 production $^{[40]}$.

The present study may add to the understanding of the effect of NE on immune function, but it is clearly necessary to elucidate the precise in vivo role of catecholamines on leukocyte function against infectious diseases and cancer.

\section{ACKNOWLEDGMENTS}

This work was supported by grants I-32914-N and CN285-00 from National Council for Science and Technology of Mexico and Autonomous University of Nuevo Leon (PAICYT), México, respectively, to RGF.

\section{REFERENCES}

1. Armstrong, M.D. and J.R. Klein, 2001. Immuneendocrine interactions of the hypothalamus-pituitarythyroid axis: integration, communication and homeostasis. Arch. Immunol. Ther. Exp. (Warsz), 49: 231-237.

2. Cole, S.W., Y.D. Korin, J.L. Fahey and J.A. Zack, 1998. Norepinephrine accelerates HIV replication via protein kinase A-dependent effects on cytokine production. J. Immunol., 161: 610-616.

3. Zigmond, R.E., M.A. Schwarzschild and A.R. Rittenhouse, 1989. Acute regulation of tyrosine hydroxylase by nerve activity and by neurotransmitters via phosphorylation. Annu. Rev. Neurosci., 12: 415-461.

4. Bravo, E.L., 1989. Metabolic factors and the sympathetic nervous system. Am. J. Hypertens., 2: 339S-344S.

5. Mills, P.J., J.E. Dimsdale, R.A. Nelesen, J. Jasiewicz, M.G. Ziegler and B. Kennedy, 1994. Patterns of adrenergic receptors and adrenergic agonists underlying cardiovascular responses to a psychological challenge. Psychosom. Med., 56: 7076.

6. Felten, D.L., S.Y. Felten, D.L. Bellinger and D. Lorton, 1992. Noradrenergic and peptidergic innervation of secondary lymphoid organs: role in experimental rheumatoid arthritis. Eur. J. Clin. Invest., 22: 37-41.
7. Radojcic, T., S. Baird, D. Darko, D. Smith and K. Bulloch, 1991. Changes in beta-adrenergic receptor distribution on immunocytes during differentiation: an analysis of $\mathrm{T}$ cells and macrophages. J. Neurosci. Res., 30: 328-335.

8. Madden, K.S., V.M. Sanders and D.L. Felten, 1995. Catecholamine influences and sympathetic neural modulation of immune responsiveness. Annu. Rev. Pharmacol. Toxicol., 35: 417-448.

9. Kohm, A.P. and V.M. Sanders, 1999. Suppression of antigen-specific Th2 cell-dependent IgM and IgG1 production following norepinephrine depletion in vivo. J. Immunol., 162: 5299-5308.

10. Zhou, M., S. Yang, D.J. Koo, D.A. Ornan, I.H. Chaudry and P. Wang, 2001. The role of Kupffer cell alpha(2)-adrenoceptors in norepinephrine-induced TNF-alpha production. Biochim. Biophys. Acta, 1537: 49-57.

11. Kaldjian, E.P., G.H. Chen and K.B. Cease, 1992. Enhancement of lymphocyte proliferation assays by use of serum-free medium. J. Immunol. Methods, 147: 189-195.

12. Hansen, M., S. Nielsen and K. Berg, 1989. Reexamination and further development of a precise and rapid dye method for measuring cell growth/cell kill. J. Immunol. Methods, 119: 203-210.

13. Gomez-Flores, R., C. Rodriguez-Padilla, R.T. Mehta, L. Galan-Wong, E. Mendoza-Gamboa and R. TamezGuerra, 1997. Nitric oxide and TNF- $\alpha$ production by murine peritoneal macrophages activated with a novel $20-\mathrm{kDa}$ protein isolated from Bacillus thuringiensis var. thuringiensis parasporal bodies. J. Immunol., 158: 3796-3799.

14. Belkowski, S.M., C. Alicea, T.K. Eisenstein, M.W. Adler and T.J. Rogers, 1995. Inhibition of interleukin-1 and tumor necrosis factor-alpha synthesis following treatment of macrophages with the kappa opioid agonist U50, 488H. J. Pharmacol. Exp. Ther., 273: 1491-1496.

15. Hernandez-Pando, R., H. Orozco, A. Sampieri, J.M. Alcocer and V. Madrid-Marina, 1996. Correlation between the kinetics of TH1/TH2 cells and pathology in a murine model of experimental pulmonary tuberculosis. Immunology, 89: 26-33.

16. Swanson, M.A., W.T. Lee and V.M. Sanders, 2001. IFN-gamma production by Th1 cells generated from naive $\mathrm{CD} 4+\mathrm{T}$ cells exposed to norepinephrine. $\mathrm{J}$. Immunol., 166: 232-240.

17. Felsner, P., D. Hofer, I. Rinner, H. Mangge, M. Gruber, W. Korsatko and K. Schauenstein , 1992. Continuous in vivo treatment with catecholamines suppresses in vitro reactivity of rat peripheral blood T-lymphocytes via alpha-mediated mechanisms. J. Neuroimmunol., 37: 47-57.

18. Josefsson, E., J. Bergquist, R. Ekman and A. Tarkowski, 1996. Catecholamines are synthesized by mouse lymphocytes and regulate function of these cells by induction of apoptosis. Immunology, 88: 140-146. 
19. Ramer-Quinn, D.S., M.A. Swanson, W.T. Lee and V.M. Sanders, 2000. Cytokine production by naive and primary effector CD4+ $\mathrm{T}$ cells exposed to norepinephrine. Brain Behav. Immun., 14: 239-255.

20. Andrade-Mena, C.E., 1997. Inhibition of gamma interferon synthesis by catecholamines. J. Neuroimmunol., 76: 10-14.

21. Green-Johnson, J.M., S. Zalcman, C.Y. Vriend, D.M. Nance and A.H. Greenberg, 1995. Suppressed T cell and macrophage function in the "reeler" ( $\mathrm{rl} / \mathrm{rl})$ mutant, a murine strain with elevated cerebellar norepinephrine concentration. Brain Behav. Immun., 9: 47-60.

22. Gan, X., L. Zhang, G.F. Solomon and B. Bonavida, 2002. Mechanism of norepinephrine-mediated inhibition of human $\mathrm{NK}$ cytotoxic functions: inhibition of cytokine secretion, target binding, and programming for cytotoxicity. Brain Behav. Immun., 16: 227-246.

23. Takamoto, T., Y. Hori, Y. Koga, H. Toshima, A. Hara and M.M. Yokoyama, 1991. Norepinephrine inhibits human natural killer cell activity in vitro. Int. J. Neurosci., 58: 127-131.

24. Kappel, M., T.D. Poulsen, H. Galbo and B.K. Pedersen, 1998. Effects of elevated plasma noradrenaline concentration on the immune system in humans. Eur. J. Appl. Physiol. Occup. Physiol., 79: 93-98.

25. Maestroni, G.J., 2002. Short exposure of maturing, bone marrow-derived dendritic cells to norepinephrine: impact on kinetics of cytokine production and Th development. J. Neuroimmunol., 129: 106-114.

26. Kalinichenko, V.V., M.B. Mokyr L.H. Graf, R.L. Cohen and D.A. Chambers, 1999. Norepinephrinemediated inhibition of antitumor cytotoxic $\mathrm{T}$ lymphocyte generation involves a beta-adrenergic receptor mechanism and decreased TNF-alpha gene expression. J. Immunol., 163: 2492-2499.

27. Hu, X.X., E.A. Goldmuntz and C.F. Brosnan, 1991. The effect of norepinephrine on endotoxin-mediated macrophage activation. J. Neuroimmunol., 3: 35-42.

28. Koff, W.C., A.V. Fann, M.A. Dunegan and L.B. Lachman, 1986. Catecholamine-induced suppression of interleukin-1 production. Lymphokine Res., 5: 239-247.

29. Spengler, R.N., R.M. Allen, D.G. Remick, R.M. Strieter and S.L. Kunkel, 1990. Stimulation of alphaadrenergic receptor augments the production of macrophage-derived tumor necrosis factor. J. Immunol., 145: 1430-1434.

30. Chi, D.S., M. Qui, G. Krishnaswamy, C. Li and W. Stone, 2003. Regulation of nitric oxide production from macrophages by lipopolysaccharide and catecholamines. Nitric Oxide, 8: 127-132.
31. Lin, W.C., P.S. Tsai and C.J. Huang, 2005. Catecholamines' enhancement of inducible nitric oxide synthase-induced nitric oxide biosynthesis involves CAT-1 and CAT-2A. Anesth. Analg., 101 (1): 226-232.

32. Javierre, M.Q., L.V. Pinto, A.O. Lima and W.A. Sassine, 1975. Immunologic phagocytosis by macrophages: effect by stimulation of alpha adrenergic receptors. Rev. Bras. Pesqui. Med. Biol., 8: 271-274.

33. Feinstein, D.L., E. Galea and D.J. Reis, 1993. Norepinephrine suppresses inducible nitric oxide synthase activity in rat astroglial cultures. J. Neurochem., 60 (5): 1945-1948.

34. Khan, M.M., P. Sansoni, E.D. Silverman, E.G. Engleman and K.L. Melmon, 1986. Beta-adrenergic receptors on human suppressor, helper, and cytolytic lymphocytes. Biochem. Pharmacol., 35: 1137-1142.

35. Friedman, E.M. and M.R. Irwin, 1997. Modulation of immune cell function by the autonomic nervous system. Pharmacol. Ther., 74: 27-38.

36. Lefkowitz, R.J., B.B. Hoffman and P. Taylor, 1995. Neurotransmission. The autonomic nervous and somatic nervous systems. In: Goodman and Gilman's The Pharmacological Basis of Therapeutics (eds G.H. Hardman, L.E. Limbard, P.B. Molinoff, R.W. Raymond and E. Gilman) pp. 105-139. McGraw-Hill, New York.

37. Hoffman, B.B. and R.J. Lefkowitz, 1990. Adrenergic receptor antagonists. In: The Pharmacological Basis of Therapeutics (eds A.G. Gilman, T.W. Rall, A.S. Nies and P. Taylor) pp. 221-243. Pergamon Press, New York, NY.

38. Hoffman, B.B. and R.J. Lefkowitz, 1990. Catecholamines and sympathomimetic drugs. In: The Pharmacological Basis of Therapeutics (eds A.G. Gilman, T.W. Rall, A.S. Nies and P. Taylor) pp. 187220. Pergamon Press, New York, NY.

39. Lomasney, J.W., S. Cotecchia, R.J. Lefkowitz and M.G. Caron, 1991. Molecular biology of alphaadrenergic receptors: implications for receptor classification and for structure-function relationships. Biochim. Biophys. Acta, 1095: 127-139.

40. Elenkov, I.J., R.L. Wilder, G.P. Chrousos and E.S. Vizi, 2000. The sympathetic nerve--an integrative interface between two supersystems: the brain and the immune system. Pharmacol. Rev., 52: 595-638.

41. Maes, M., A. Lin, G. Kenis, B. Egyed and E. Bosmans, 2000. Negative immunoregulatory effects of noradrenaline through alpha2-adrenoceptor activation. Neuroendocrinol. Lett., 21: 375-382. 